\title{
Editorial
}

\section{A estratégia das Redes de Atenção à Saúde no âmbito do Sistema Único de Saúde}

\author{
Elisabete Ferreira Mângia ${ }^{1}$, Selma Lancman ${ }^{1}$
}

O lançamento das diretrizes para a organização das Redes de Atenção à Saúde no âmbito do Sistema Único de Saúde (SUS) responde ao objetivo de promover a integração dos serviços e ações de saúde para assegurar a integralidade, continuidade, humanização, qualidade e responsabilidade. Visa também incrementar o acesso, equidade, eficácia clínica e sanitária; e eficiência econômica, ou seja, a proposição das Redes reafirma e aprimora os princípios e diretrizes do SUS além de definir com clareza seu modelo operativo (Brasil, 2010).

Justifica essa medida a necessidade de reorientar o sistema de saúde para a mudança do perfil epidemiológico, que, no Brasil, tem configuração singular ao conjugar características de países subdesenvolvidos e desenvolvidos, com a tendência de predomínio de doenças crônicas e não mais agudas (modelo que formatou a maior parte dos sistemas de saúde no mundo), somada a um quadro ainda não equacionado de infecções, desnutrição e problemas de saúde reprodutiva, além do crescimento das causas externas decorrentes da violência e dos acidentes de trânsito (Vilaça, 2010).

A estratégia das Redes se baseia no reconhecimento de que, apesar dos avanços, o "modelo de atenção à saúde vigente fundamentado nas ações curativas, centrado no cuidado médico e estruturado com ações e serviços de saúde dimensionados a partir da oferta, tem se mostrado insuficiente para dar conta dos desafios sanitários atuais e, insustentável para os enfrentamentos futuros" (Brasil, 2010). Nesse contexto, um dos problemas principais a ser superado é a intensa fragmentação de serviços, programas e práticas clínicas

Mais do que um conjunto de diretrizes os conteúdos apresentados na proposição das Redes de Atenção à Saúde se coloca como importante síntese dos principais eixos teóricos e técnicos que devem orientar a qualificação do Sistema com ênfase ao processo de integração e na afirmação das principais estratégias orientadoras de práticas de saúde centradas nos usuários e em suas necessidades (Vilaça, 2010)

Coloca também, para todo o conjunto da rede e não mais apenas para a saúde mental e atenção primária, a centralidade da construção do projeto terapêutico singular e demais componentes para a qualificação do modelo assistência, especialmente aqueles que configuram as tecnologias relacionais e de trabalho colaborativo, tais como, o acolhimento, a escuta qualificada, o vínculo e a responsabilização, no contexto do trabalho interprofissional.

A proposta das Redes reafirma a centralidade de atenção primária e redefine os atributos e funções esperadas de cada área de aplicação, classificadas em cuidados primários, atenção especializada e cuidados de urgência e emergência. Também estabelece as diretrizes e componentes das diversas linhas de cuidado.

Como iniciativa complementar, foi lançada em dezembro de 2011, a proposição para organização da Rede de Atenção Psicossocial destinada as pessoas com sofrimento ou transtorno mental e com necessidades decorrentes do uso de crack, álcool e outras drogas (Brasil, 2011).

Considerada prioritária, a Rede de Atenção Psicossocial se justifica pela necessidade do SUS em oferecer serviços de saúde mental integrados, articulados e efetivos nos diferentes pontos de atenção, ampliando e destinando recursos também para as pessoas com demandas decorrentes do consumo de álcool, crack e outras drogas. Nesse contexto, são reforçadas as diretrizes e princípios que privilegiam a ética, o respeito aos direitos de cidadania, o acesso e a qualificação das ofertas, já anteriormente estabelecidos pela Política de Saúde Mental e pela Lei 10216. A proposta amplia e diversifica as modalidades de ações e serviços especialmente destinados ás pessoas com problemas decorrentes do uso prejudicial de álcool e outras drogas. Assim, se soma aos serviços já preconizados pela Política de Saúde Mental: as equipe de consultório de rua, os serviços de acolhimento e os serviços residenciais de caráter transitório (Brasil, 2001).

Esse conjunto de proposições sistematiza o que de mais avançado se produziu no percurso teórico e técnico de construção do SUS, mas requer grande esforço para sua implementação, uma vez que sofistica a lógica de funcionamento proposta para o sistema e exige de seus executores um alto grau de sensibilidade, disponibilidade e formação para a mudança e superação dos graves problemas hoje presentes nas redes assistenciais.

O projeto da constituição das Redes de Atenção à Saúde é fortemente dependente da formação dos profissionais e dos processos

\footnotetext{
${ }^{1}$ Editoras da Revista de Terapia Ocupacional da USP.

Endereço para correspondência: e-mail revto@usp.br
} 
de educação permanente. Especialmente no contexto da Rede de Atenção Psicossocial na qual a organização dos serviços e ações depende muito mais de recursos humanos do que de equipamentos tecnológicos.

A ancoragem em evidencias internacionais em diálogo com a experiência nacional de implantação do SUS, situa o Brasil em um patamar ótimo em termos de projeto político, mas também revela a necessidade de desenvolvimento de estudos e pesquisas de diversas naturezas, especialmente no âmbito da Rede de Atenção Psicossocial.

Nesse âmbito, preocupa o elevado nível de sofisticação e exigências colocadas pelo novo projeto, muito distante da capacidade real das equipes e dos serviços. Essa é uma questão que não invalida a proposição, mas coloca a importância central do papel da gestão municipal e da formação de recursos humanos como garantia para a sua realização e especialmente, da articulação entre ensino, pesquisa e serviços.

Para os pesquisadores, docentes e profissionais da Terapia Ocupacional e das áreas afins cabe refletir sobre como contribuir com esse processo e nesse sentido, a Revista de Terapia Ocupacional da USP se coloca como mais um canal a para a apresentação e divulgação da produção de conhecimento nesse campo.

\section{REFERÊNCIAS}

Brasil, MS, PORTARIA GM/MS No 3.088, DE 23 DE DEZEMBRO DE 2011 - Institui a Rede de Atenção Psicossocial para pessoas com sofrimento ou transtorno mental e com necessidades decorrentes do uso de crack, álcool e outras drogas, no âmbito do Sistema Único de Saúde.

Brasil, MS, PORTARIA GM/MS No 4.279, DE 30 DE DEZEMBRO DE 2010 Estabelece diretrizes para a organização da Rede de Atenção à Saúde no âmbito do Sistema Único de Saúde (SUS).

Vilaça, E.M. As redes de atenção à saúde, Ciência \& Saúde Coletiva, 15(5):2297-2305, 2010 